\title{
Assessing Service Quality in the Hospitality Industry
}

\author{
Brigid Appiah Otoo and Edward Fekpe
}

\begin{abstract}
The quality of service operations can be measured by waiting time because of its impact on customer's perception of service efficiency and operational capabilities. Hotels and restaurants are broadly rated based on their facilities and quality of cuisine respectively. This study assesses the quality of service of the hospitality industry (hotels and restaurants) using waiting time as a proxy. It explores how service quality relates to star ratings. The study is based on data from 149 restaurants and 116 hotels in Ghana. It is concluded that there is no correlation between the star rating of hotels and restaurants and the service quality measured in terms of waiting times.
\end{abstract}

Keywords - waiting time, service quality, business rating, customer satisfaction.

\section{Introduction}

The quality of service operations can be measured by waiting time because of its impact on customer satisfaction and operational capabilities. For businesses, the costs of waiting result in lower productivity and competitive disadvantage. For society, the costs are wasted resources and reduced quality of life. Thus the adequacy of waiting time has strong effects on the quality of service and productivity (efficiency). It is therefore important to consider the impacts of waiting time in service system design and management.

Waiting lines are formed whenever the current demand for a service exceeds the current capacity to provide that service. Considering the difficulty in accurately predicting arrival pattern of customers for service and/or how much time is required to provide service to each customer, accurate decision regarding the capacity to be provided is made quite difficult. Excess service capacity involves excessive costs due to underutilization. Insufficient capacity to meet peak loads causes waiting lines to become excessively long and customers may even quit the waiting lines. The ultimate goal is to achieve an economic balance between the cost of service (i.e., cost of idle facility and employee) and costs associated with waiting for the service (i.e., social cost and cost of lost customers).

The planning and capacity analysis of service operations uses queuing theory. This is a well established and proven theory that is applicable to a wide range of service operations including banks, restaurants, hotels, traffic management and telecommunication systems. The maximum permissible number of customers that it can contain characterizes a queue. This also could be finite or infinite. In most practical

Ghana Institute of Management and Public Administration Accra, Ghana situations, it is finite. Queue discipline refers to the order in which members of the queue are selected for service. The order is usually on a first-come-first-served basis. However, priority-discipline models give priority to rush jobs and important customers over others and follow random selection, priority selection or last in first out.

The hospitality industry in Ghana is attracting a lot of attention given the apparent political stability and attendant attraction of foreign investors. The growth in tourism has the potential of creating jobs and increasing its contribution to the national Gross Domestic Product (GDP). Given the increasing number of hospitality facilities and the level of competition, the quality of service delivery becomes a discriminating factor for customers and a measure of business success. While hospitality is a global industry, the quality of service delivery varies among nations, regions, and even among facilities in the same category. In a developing country such as Ghana, the quality of service can be a critical competitive strategy. Currently, there is no documented evidence of how the quality of service is used as a measure of performance or competitive discriminator in the hospitality industry in less developed countries.

As noted earlier, customers generally dislike waiting for service. While it has been established that waiting causes irritation and may cloud a consumer's perception of an organization's efficiency or performance, the threshold of waiting time beyond which it becomes unacceptable needs to be established. The question then is what is an acceptable waiting period for service in an organization that offers hospitability services? Is this threshold the same for hotels and restaurants; is this threshold the same for hotels of all classes or categories? This paper examines service quality measured in terms of waiting time at check in and check out at hotels; and waiting times for restaurant service. The paper also examines the relationships between star ratings of hospitality businesses (hotels and restaurants) and the quality of services they offer.

\section{Literature Review}

Balancing customers' needs and/or wants with the organization's service capacity is a challenge for most businesses. Federal Express aptly notes in fortune magazine that: "Waiting is frustrating, demoralizing, agonizing, aggravating, annoying, time consuming and incredibly expensive." (Fortune: 28 July 1980, p. 10). This is an opinion most service customers share. Long waiting time continues to be one of the most stressful service encounters that customers have to deal with. Although many delays are caused by inefficiencies in the service delivery process, waiting in some service situations seems to be almost unavoidable. Waiting is 
an almost inescapable part of a consumer's service encounter, whether in the queue at the checkout point in a retail store, placing an order, or making an enquiry. According to Taylor (1994), waiting commences when a customer is ready for the service encounter and ends when personal interaction with the service provider commences.

When customers wait longer than expected, they become bored and inevitably assign some cause for the delay (Van Riel et al., 2012). Negative emotions become even more severe when the reason for the wait is attributed to slow or incompetent human resource or processes (Hartley and Ward, 2006). Mostly, waiting is resented and causes irritation, which creates a negative emotional state (Kostecki, 1996) that clouds a consumer's perception of an organisation's image and efficiency (Deeter-Schmelz et al, 2000) and the service experience (Verma et al, 1999).

Customers often have to wait during the process of acquiring and consuming many products and services. These waiting experiences are typically negative and have been known to affect customers' perception and overall satisfaction with the product or service, which subsequently affect the organisation's efficiency and productivity (Weinberg, 2000).

Kumar and Krishnamurthy (2008) advise that organisations, particularly service providers, could benefit from initiatives that would reduce customers' frustrations due to long queues and extensive waiting times. However, each organisation is unique even though each needs to achieve their goals. Due to the complexity of current business dynamics, many organisations face the challenge of how to identify a solution to customer waiting time in order to influence customer perception of organisational efficiency. Continual organizational assessment is therefore necessary for management to identify internal weakness and strengths, to make quick decisions and to react quicker for course correction, particularly in reducing waiting time for organisational efficiency. There is therefore the need to explore a chain of causes-and-effects that drive the institution results in order to make corrective actions to address customer waiting and quality of service issues.

Maister (1985) observed that the waiting-line experience in a service facility significantly affects customers' overall perceptions of the quality of service provided. Pruyn and Smith (1998) noted that objective waiting time influences satisfaction through perceived waiting time, and improving the attractiveness of the waiting environment could reduce negative effects on satisfaction. Also, while customers believe both quality and value are worth waiting for, there comes a point where an unacceptable wait begins to affect their perception of quality.

According to $\mathrm{Yu}$ (1992), hotel rating systems differ markedly from country to country and the criteria employed often reflect local cultural differences in values and preferences. Most countries adopt rating systems that are consistent across the land. For instance, Ching-Shu and LouHon (2007) observed that, while the hotel industries of the United Kingdom and United States of America employ entirely different approaches, both have effective rating systems that can be consulted by other countries regarding method of implementation, rating mode, main content, and service quality criteria.

Traditionally, ratings of the facilities of hospitality businesses were emphasized at the expense of service quality. However, recent studies show that, service quality is increasingly being emphasized worldwide (Callan 1995). Callan (1990) observed that, even as hotel rating systems have begun to emphasize service quality, measurement of that quality can be subjective, and ratings can vary greatly. Typically, the service quality assessment includes such aspects as warmth of welcome; the standard of the furnishings, fittings, and décor as well as the standard of meals and their presentation (Ching-Shu \& Lou-Hon 2007). Even though service quality is assessed in various ways, the waiting time effect is barely considered even though it impacts the customer's experience significantly.

\section{Methodology}

The underlying premise of this study is that, the quality of service in hospitality businesses should be a major factor in determining the rating of the business. Therefore waiting time, which forms a significant part of a customer's perspective about the quality of business, should impact the quality rating of a hospitality business. This research is intended to assess how quality of service, measured by waiting time, relates to the star rating of the business. The study is based on the following hypotheses:

H1: the star rating of a hotel or restarurant is a reflection of the expected quality of service measured in terms of the waiting time.

H2: the quality of identical services offered is same for both restaurants and hotels of the same start rating.

The study was based on the analysis of data from selected service providers stratified by the type of hospitality service (hotels, restaurants) and ranking (e.g., 5-star, 3-star etc.). The study was conducted through focused interviews and administration of questionnaires to respondents.

For the hotels, data was collected on the waiting times for check in and check out at the front desks; waiting times for meal order to be served and to receive bill at their restaurants. For standalone restaurants, data was collected on waiting times for customers to be served (after they have placed an order) and to receive bills (after requesting for them). The focus is on these sets of waiting times because they depict requesting service and paying for the service received.

A total of 265 respondents were included in the sample that comprised of 149 standalone restaurants and 116 hotels of different star ratings. Data was collected in the month of June 2015, which is the peak of the holiday season for most tourists visiting Ghana. This presented a good opportunity to capture data from the typical consumer of the hospitality market. The data was then analyzed with the SPSS software. 
Proc. of The Fifirth Intl. Conf. On Advances in Economics, Management and Social Study - EMS 2016

Copyright (C) Institute of Research Engineers and Doctors, USA .All rights reserved.

ISBN: 978-1-63248-089-7 doi: 10.15224/ 978-1-63248-089-7-35

Queue discipline was first-come-first-served and the length was infinite. It is assumed that the behaviour of the queues are identical regardless of the queuing model that could best describe the situation. For example, the number of servers and the arrival rates were not taken into account. The analysis did not consider the theoretical queuing models.

\section{Discussion of Findings}

The waiting times for various star ratings in both hotels and restaurants were summarized in graphs as shown in Figures 1-6. From the graphs, it is observed that for hotel check-in and check-out, the typical waiting time was 1-10 minutes. Less than $20 \%$ of the respondents indicated 'less than 1 ' minute as the waiting time for check-in and check out (Figures 1 and 2). It is also noted that the trend is identical for all star ratings. In other words, the waiting time to receive check-in and check out service does not depend on the star rating of the hotel.

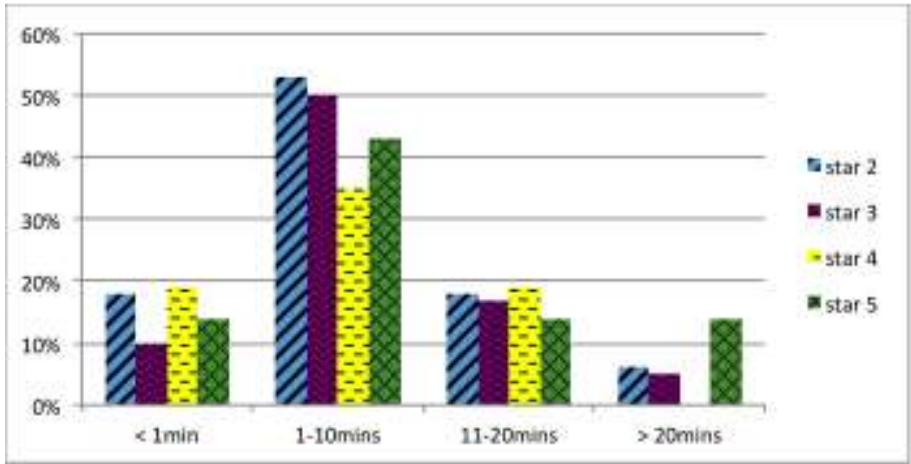

Figure 1. Hotel check in waiting time

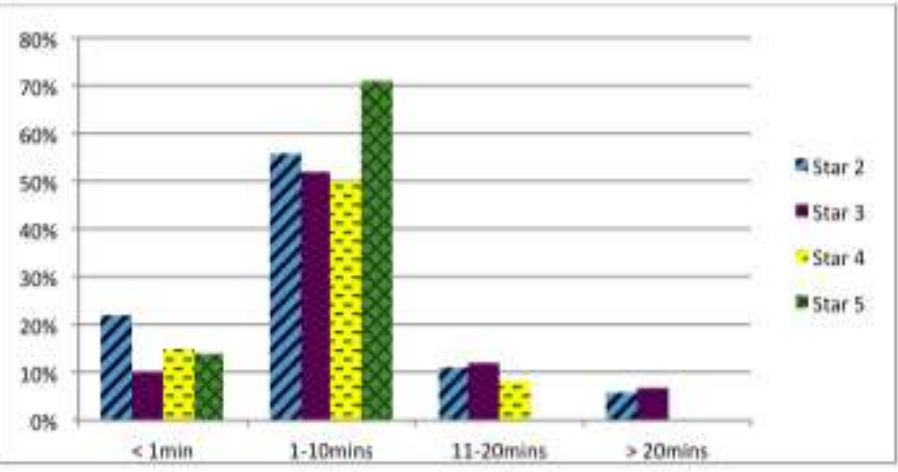

Figure 2. Hotel check out waiting time

Figures 3 and 4 show the waiting time to be served in hotel and standalon restairants. It is interesting to note that the distribution of the waiting times are varibale but similar for hotels and restaurants. Though the time of day when service was received was not captured, it could be a contributing factor to the variability in the waiting times for this service. Furthermore, the party size and the complexity of the orders could also explain the wider variability in the waiting times to be served after ordering.

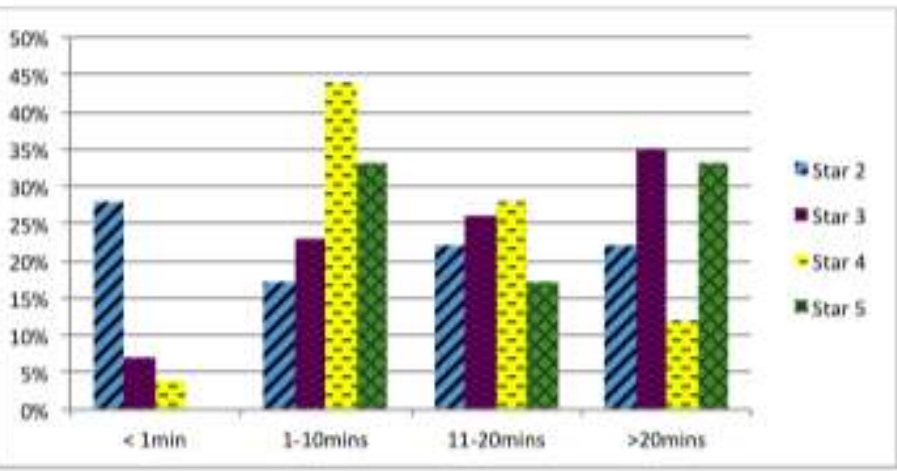

Figure 3. Hotel (restaurant service) order waiting time

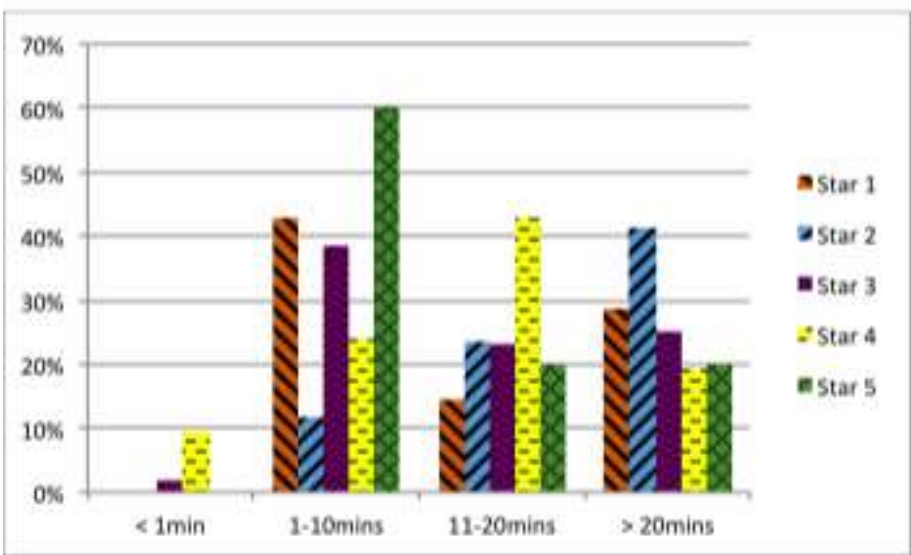

Figure 4. Restaurant order waiting time

The distribution of the waiting times is similar for check out from the restaurant services (i.e., requesting for orders and receiving the bills) for both hotel and standalone restaurants (Figures 5 and 6). However the variability is less than that for the waiting time to be served. For both types of facilities, the median waiting time is 1 to 10 minutes regardless of the star rating.

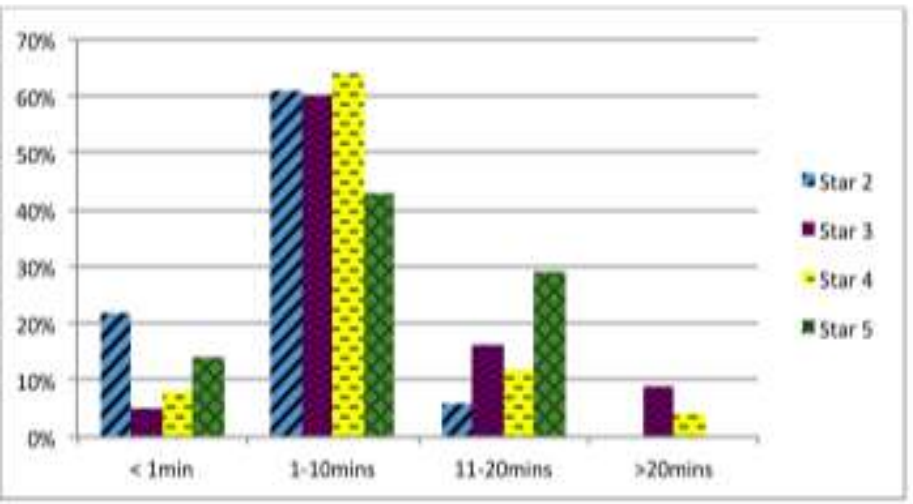

Figure 5. Hotel (restaurant service) bill waiting time 
Proc. of The Fifirth Intl. Conf. On Advances in Economics, Management and Social Study - EMS 2016

Copyright (C) Institute of Research Engineers and Doctors, USA .All rights reserved.

ISBN: 978-1-63248-089-7 doi: 10.15224/ 978-1-63248-089-7-35

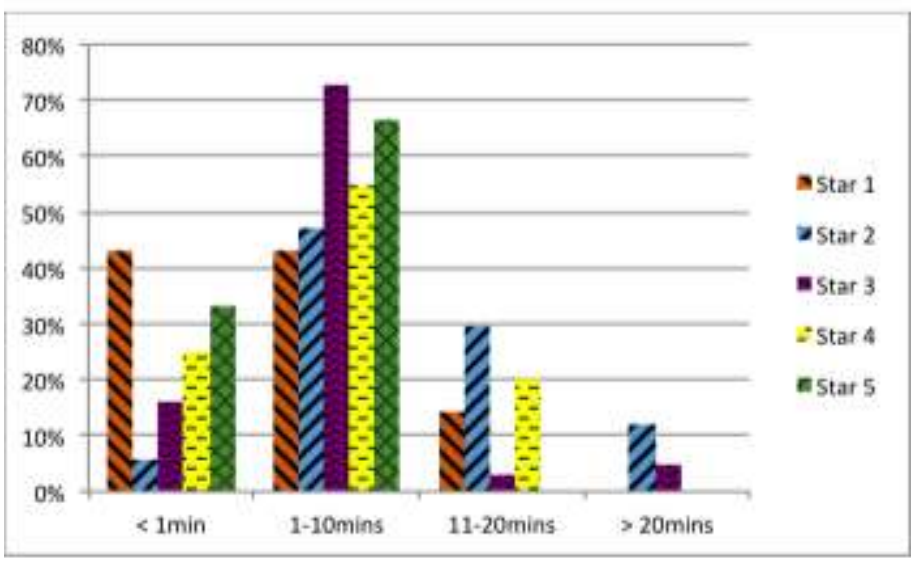

Figure 6. Restaurant bill waiting time

Further analyses were carried to determine the degree of correlation between the waiting times and the star ratings. Cross tabulation using the Pearson Chi square correlation analysis was used. The results summarized in Table 1 show the chi-square values, the degree of freedom (df) and the pvalues for the various facilities and services.

The results clearly indicate that there is no significant difference between the various star hotels and their check in or check out waiting time at $95 \%$ significance level i.e., the pvalues are greater than 0.05 in all cases.

TABLE I. SUMMARY OF CROSS TABULATION RESULTS

\begin{tabular}{|c|l|c|c|c|}
\hline Facility & \multicolumn{1}{|c|}{ Service } & $\boldsymbol{X}^{\mathbf{2}}$ & $\boldsymbol{d f}$ & $\boldsymbol{p}$-value \\
\hline Hotel & Check in & 13.99 & 18 & 0.729 \\
\hline Hotel & Check out & 11.81 & 15 & 0.693 \\
\hline $\begin{array}{c}\text { Hotel } \\
\text { (Restaurant) }\end{array}$ & $\begin{array}{l}\text { Check in } \\
\text { (place order) }\end{array}$ & 18.06 & 15 & 0.260 \\
\hline $\begin{array}{c}\text { Hotel } \\
\text { (Restaurant) }\end{array}$ & Check out & 9.77 & 12 & 0.636 \\
\hline $\begin{array}{c}\text { Restaurants } \\
\text { (standalone) }\end{array}$ & $\begin{array}{l}\text { Check in } \\
\text { (place order) }\end{array}$ & 19.81 & 20 & 0.470 \\
\hline $\begin{array}{c}\text { Restaurnats } \\
\text { (Standalone) }\end{array}$ & Check out & 29.04 & 24 & 0.201 \\
\hline
\end{tabular}

Based on the results in Table 1, the hypothesis H1, which suggests that the star rating of a hotel or restarurant is a reflection of the expected quality of service measured in terms of the waiting time, is rejected. This means that the star rating of a hotel or restaurant is not a reflection of the expected quality of service measured in terms of the waiting time. This is contrary to the general perception that the expected quality of service should be consistent with the star rating. This is a fact, which customers must know when considering a service.

The discussions presented above further suggest that the hypothesis $\mathrm{H} 2$ is also rejected. In other words, the quality of identical services offered by hotels is not necessarily the same for standalone restaurants of the same star rating.

This is limited study where waiting time is used as the only measure of service quality. Other factors affecting waiting time at a service desk were not taken into account. For example the time of day, the number of servers, experience (or knowledge) of the servers, and details of the service requested are contributing factors. This study focused on the actual waiting times and assumes the influences or impacts of the individual and collective effects of these factors are negligible.

From our study, the typical waiting time for all types of services irrespective of the star rating of the hotel or restaurant was 1 to 10 minutes. This suggests that, future studies may consider breaking down this time interval for further analysis to gain more accurate measure of exact waiting times and identify ways of reducing waiting them.

\section{v. Conclusions}

From the results clearly indicate that there is no correlation between quality of service using waiting time as proxy and the star rating of hospitality businesses. Even though the quality of service has a significant influence on a customer's perception about a hospitality business, it has very little impact on how the hotels were rated. Also the quality of service at facility of given star rating cannot be expected at another facility with same star rating.

\section{References}

[1] Taylor, S., (1994). "Waiting for service: The relationship between delays and evaluations of service", Journal of Marketing, 58(4): 56-69

[2] Van Riel A.C.R., Semeijn, J., Ribbink, D., Bomert-Peters, R., (2012) "Waiting for service at the checkout: Negative emotional responses, store image and overall satisfaction", Journal of Service Management, 23(2): $144-169$

[3] Hartley, N \& Ward, T. (2006). "The effect of waiting and 'pushy' sales staff on customers' satisfaction". [Online] Available from: http:// www.acrwebsite.org/volumes/ap07/13077.pdf [Accessed: 2016-02-06].

[4] Kostecki, M., (1996). "Waiting Lines as a Marketing Issue", European Management Journal, 14(3) $1: 295-303(9)$

[5] Deeter-Schmelz, D.R., Moore, J.N., Goebel, D.J., (2000). "Prestige Clothing Shopping by Consumers: A Confirmatory Assessment and Refinement of the "Precon" Scale with Managerial Implications", Journal of Marketing Theory and Practice, 43-58

[6] Verma, S., Larson, R., (1999). "How children and adolescents spend time across cultural settings of the world: Work, play and developmental opportunities". Psychological Bulletin, 125: 701-736.

[7] Weinberg R.A., Hanahan, D., (2000). "The hallmarks of cancer." Cell 100(1): 57-70

[8] Kumar, P., Krishnamurthy, P., (2008). "The impact of service-time uncertainty and anticipated congestion on customers' waiting-time decisions", Journal of Service Research 10 (3): 282-292

[9] Maister, D.H., (1985) "The Psychology of Waiting Lines," in The Service Encounter, (J. Czepiel, M. Solomon and C. Suprenant, eds.) 1985 pp.113-123 Lexington, Lexington, MA

[10] Pruyn, A. and Smidts, A. (1998), "The effect of waiting on satisfaction with the service: beyond objective time measurements", International Journal of Research in Marketing, 15(4): 321-34

[11] Yu, L., (1992). Seeing stars: China's Hotel-rating system. Cornell Hotel and Restaurant Administration Quarterly 33 (5): 24-27

[12] Ching-Shu S., Lou-Hon S., (2007). "Taiwan's Hotel Rating System: A Service Quality Perspective" Cornell Hotel and Restaurant Administration Quarterly, 48 (4): 392-401

[13] Callan, R. J. (1995). Hotel classification and grading schemes: A paradigm of utilization and user characteristics. International Journal of Hospitality Management 14 (3): 271-84 
Proc. of The Fifirth Intl. Conf. On Advances in Economics, Management and Social Study - EMS 2016

Copyright $(\odot$ Institute of Research Engineers and Doctors, USA .All rights reserved.

ISBN: 978-1-63248-089-7 doi: 10.15224/ 978-1-63248-089-7-35

[14] Callan, R. J., (1990). "Hotel award scheme as a measurement of service quality: An assessment by travel-industry journalists as surrogate consumers". International Journal of Hospitality Management 9 (10): $45-48$

About Authors:

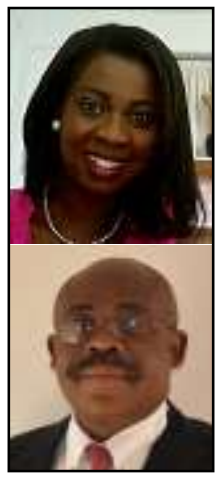

"The star rating of a hotel or restaurant is not a reflection of the expected quality of service measured in terms of the waiting time. This is contrary to the general perception that the expected quality of service should be consistent with the star rating". 